\title{
Removal of barriers to care result in improved utcomes for manual laborers with compressive neuropathies
}

\begin{abstract}
Background: We have found that, in certain social climates, barriers to care prevent the appropriate implementation of the spirit and legislative intent of the Workers Compensation system. It is our belief that procedural delays are used to limit access to care in certain environments that ultimately increases the cost to the system. Methods: TMMI for workers exposed to heavy manual tasks given early medical access is compared to workers denied access with workers' comp savings demonstrated.

Results: Workers that lacked access to a physician at the time of declaring that they were unable to perform their job function due to upper extremity pain reached MMI (case closed) on average in 47 months and would have collected over $\$ 250,000$ as the state of Illinois pays $66 \%$ of the employee's salary during the TTD period resulting in $\$ 64,636 /$ year for a worker with a $\$ 100,000 / y r$ salary. In contrast, workers that were provided with early access to a physician achieved MMI on average within 5.7 months, would collect around $\$ 30,700$ on average and be able to return to work in some capacity. Therefore, shortening TTD time by providing rapid medical access would appear to be fiscally sound $(>\$ 200,000$ TTD cost savings).

Conclusion: Removal of barriers to medical care should be considered in cases of severe upper extremity musculoskeletal disorders. Everyone benefits from the financial savings while workers have reduced surgical stress and recovery time.
\end{abstract}

Volume 2 Issue 2 - 2015

\author{
Blair A Rhode, William S Rhode, Brent \\ Rhode \\ Orland Park Orthopedics, USA
}

Correspondence: Blair A Rhode, Orland Park Orthopedics, 16450 S 104th AV, Orland Park, Illinois 60467, USA, Tel 708-364844I, Email blairbones@gmail.com

Received: January 19, 2015 | Published: March 10,2015

\section{Introduction}

Workers' Compensation traces its origins back to Germany, where Chancellor Otto Von Bismarck introduced a compulsory state run accident compensation system in 1884 . Nine states passed workers' compensation legislation in 1911, and by 1948 every state had some form of workers' comp law on the books. Workers' Compensation is a state mandated no-fault systemform of insurance that ensured that workers injured at work would receive compensation without delay and without regard to fault. It was started in response to serious societal problems caused by a dramatic rise in the number of people injured in industrial settings.It is a benefit provided in exchange for mandatory relinquishment of the employee's right to sue his or her employer under the common civil law of negligence.

The relationship between the legitimately injured/sickened worker and the insurance carrier paying the medical bills and other compensation is by nature somewhat adversarial. The injured worker wants quality medical treatment to enable a full recovery, and the insurance carrier wants as inexpensive resolution as possible. Disputes can arise when the claims administrator contests employee claims. We have found that, in certain social climates, barriers to care prevent the appropriate implementation of the spirit and legislative intent of the Workers Compensation system. We believe that this spirit is to achieve timely treatment of the injured worker such that the earliest return to work in an economical fashion can be achieved. It is our belief that procedural delays are used to limit access to care in certain environments that ultimately increases the cost to the system.

We studied a cohort group of manual laborers that demonstrated findings consistent with compressive neuropathies of the median and/ or ulnar nerves resulting in carpal and/or cubital tunnel syndromes
(CTS and CuTS). All study participants' job exposure met the criteria for causation as described by the force, repetition and vibration required to perform the work related tasks. ${ }^{1}$ Maximum medical improvement is that time at which the patient's improvement has reached a plateau. Time to maximum medical improvement (TMMI) was measured in a population of laborers after the barriers to care were removed. A comparison group was obtained via a random sample of workers that lacked access to a physician at the time of declaring that they were unable to perform their job function due to upper extremity pain. We also analyzed medical costs between these two groups and cost of the time of total temporary disability or TTD, which is the payment of wage substitute while off from work.

\section{Materials and methods}

We analyzed a cohort of workers that were exposed to manual tasks $(\mathrm{N}=40)$ that met the causation criteria as described by NIOSH [1] including a group of 12 chip and grind workers. NIOSH concluded that workers exposed to jobs that included force, repetition and vibration had an association with carpal and cubital tunnel syndrome. Patients presented with complaints of palmar wrist pain with numbness and parasthesias to the thumb, index and long finger (CTS) or the ring and little finger (CuTS). Patients also demonstrated clinical findings consistent with CTS (positive Tinels and Phalens at the wrist) or CuTS (Tinels at the elbow).

\section{Surgery}

Surgical procedures included: 9 for unilateral CTS, 9 for bilateral CTS, 5 for unilateral CTS/CuTS, 4 for bilateral CuTS, and 13 for bilateral CTS/CuTS. Of 57 median nerve decompressions for CTS, $84 \%$ had positive electrodiagnostics (+EDX). Decompressions when 
the EDX was negative were performed after the patient stated they did not want to deal with the pain any longer and clinical symptoms warranted it. Of 32 decompressions of the ulnar nerve for CuTS ( $\mathrm{N}=32)$ $50 \%$ had + EDX. The - EDX cases were typically managed based upon the patients' subjective complaints and clinical symptoms. Three CTS and four CuTS that had +EDX were managed conservatively. When clinical examination (numbness, burning, tingling or pain in the first $3 \frac{1}{2}$ digits) usually in combination with +EDX indicated the need for decompression of the median nerve, pressure was relieved by transecting the transverse ligament using a mini-open surgical approach. Similarly, the ulnar nerve was decompressed via an open approach at the medial epicondyle when clinical examination and reported symptoms indicated it. As far as decompressions when there was a-EDX, it has been previously demonstrated that paresthesias were resolved by nerve release at the elbow. ${ }^{2,3}$ A study concluded that electromyography and nerve conduction velocity tests are not necessary for identification of patients likely to obtain relief from surgery for CuTS after conservative treatment failed. ${ }^{4}$ Agreement between clinical screening procedures and sensory nerve testing was found to be poor and it was suggested that new methods were required for the detection of CTS [5]. This results in part due to the cost of EDX testing in epidemiological studies where there are a high percentage of negative outcomes.

\section{Patient management and cost savings}

Patients managed surgically were followed throughout their postoperative course. Time to maximal medical improvement (TMMI) was measured from the date that barriers to care were removed (date of first office visit). We compared these results to our control group of 77 workers randomly sampled from patients that lacked access to a physician at the time of declaring that they were unable to perform their job function due to upper extremity pain. We also analyzed costs based upon TTD benefits and medical costs (surgeon fees, facility fees). An analysis was also made of the costs associated with simultaneous ipsilateral carpal and cubital tunnel surgery vs staged procedures as we believe that this treatment method affords significant cost savings. We compared these results to the costs resulting from TTD status in the control group. No medical cost data could be obtained from the controls as they lacked access to medical care.

\section{Results}

The average TMMI for workers once they were provided with medical access was 5.7 months with a mode of 4.3 months while the workers denied medical access had an average TMMI or in their instance 'case closed' of 46.8 months (Figure 1). There was a longer TMMI (6.4 mo, range: $3.7-10.8, \mathrm{~N}=12)$ for the chip and grid workers than for those classified as manual laborers (5.1 mo, range: 2.8-12.6, $\mathrm{N}=28)$. The subset of unilateral CTS $(\mathrm{N}=15)$ has a TMMI of 5.3 months. TMMI of the subset of bilateral CTS $(\mathrm{N}=25)$ was 5.9 months. Cost for 5.7 months of TTD benefits for injured workers with $\$ 100,000$ per year salaries give nearly medical access would be $\$ 30,702$. The workers denied medical access would have an average TTD cost of $\$ 250,000$ as a result of a 46.8 month TMMI (where TMMI is defined as case closed).

The medical cost based upon the 2009 Illinois Workers Compensation ambulatory Professional Services Fee schedule 6 was $\$ 2397.67$ for carpal tunnel, \$3373.34 for cubital tunnel, and \$ $2397.67+3373.34 / 2$ for simultaneous ipsilateral carpal and cubital tunnel release. When both carpal and cubital symptoms are bilateral, performing these procedures in a staged manner implies 4 surgeries resulting in additional medical costs of $\$ 3373.34$. Facility costs for each service $=\mathrm{C}$ except when the carpal/cubital operation are performed the same day, in which case the facilities reimbursement drops to $C+1 / 2 C$. In some cases only a single facility fee $(C)$ is provided. Therefore, the facility fee savings to the provider is either $\mathrm{C} / 2$ for unilateral CTS/CuTS or as much as C for bilateral CTS/ CuTS. For bilateral CTS/CuTS the potential savings based on the Professional Services and Facilities fees would be substantial, if single facility fee reimbursement is invoked it would be $2 \mathrm{C}$.

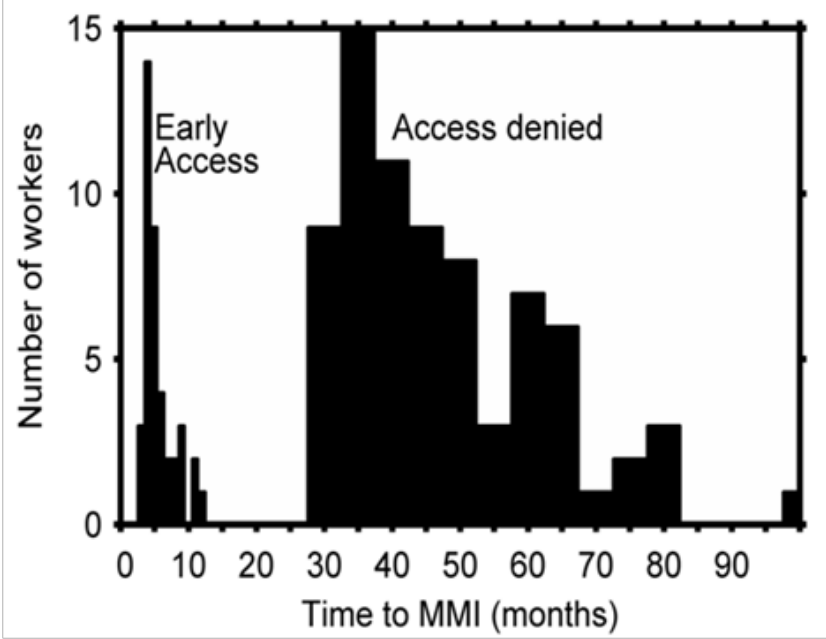

Figure I Comparison of the distribution of TMMls for injured workers with early medical access measured from the time seen by a specialist (mean $=5.7$ months, $\mathrm{N}=40$ ) versus the distribution of times to case closed for injured workers (mean $=47$ months, $\mathrm{N}=77$ ) that were denied medical access.

\section{Discussion}

\section{Upper extremity musculoskeletal disorders}

Numerous studies have documented the relation between work exposure and upper extremity musculoskeletal disorders with the greatest focus on CTS. The relative risk of CTS based on occupation has been shown to be greater than 13 for workers performing mechanical machinery assembly, building construction, stone and sand quarrying, and the manufacture of transport equipment. ${ }^{7}$ The percentage of workers exhibiting vibration syndrome when working as riveters, chippers and grinders exceeds $20 \%$ in some studies and increases with years of exposure to a range of $33-47 \%{ }^{8,9}$ Key risk factors for CTS in industrial setting are occupational. ${ }^{10}$ In fact, the relation of CTS to repetitive tasks and vibration exposure has been exhaustively documented. ${ }^{11-17}$

In this study, patients typically had +EDX along with severe symptoms that were clinically assessed and self-reported. When electro diagnostics were negative, clinical evaluation was used to determine the necessity for surgery. This is supported by reports of the surgical treatment of CTS in patients with normal nerve conduction..$^{3,18,19}$ Because the hand and arm work in conjunction, stress is placed at multiple sites in the upper extremity which can result in multilevel nerve compression often unrecognized. ${ }^{20-22}$ It was pointed out in the introduction of successful decompression of the ulnar nerve in patients lacking or having negative EDXs. 


\section{Workers' comp considerations}

Workers' Compensation was instituted in the United States at the turn of the century as a no fault system of social legislation. The spirit of the law is to provide compensatory medical care for employees who are injured in the course of employment, in exchange for mandatory relinquishment of the employee's right to sue his or her employer for the tort of negligence. Unfortunately, we have found that the system fails the injured worker in certain environments. By implementing procedural roadblocks in the form of initial claim denial and delay methods, the injured worker finds himself/herself in a battle of attrition. By delaying treatment and compensation benefits, the injured workers are "starved out" of their access to care and often walk away from their claim or accept a payout without treatment.

Workers that lacked access to a physician at the time of declaring that they were unable to perform their job function due to upper extremity pain reached MMI (case closed) on average in 47 months and would have collected over $\$ 250,000$ as the state of Illinois pays $66 \%$ of the employee's salary during the TTD period resulting in $\$ 64,636 /$ year for a worker with a $\$ 100,000 / y r$ salary. In contrast, workers that were provided with early access to a physician achieved MMI on average within 5.7months, would collect around $\$ 30,700$ on average and be able to return to work in some capacity. Therefore, shortening TTD time by providing rapid medical access would appear to be fiscally sound.

We have shown that removal of barriers to care can produce a significant decrease in TMMI. This also results in a significant cost savings in TTD benefits of over $\$ 200,000$ relative to the control group. A lesser though not negligible amount of savings in professionaland facility- fees can be attained when median and ulnar nerve decompressions are performed the same day depending on whether severe CTS and CuTS are present unilaterally.

Perhaps as important as the costs of WC for upper extremity musculoskeletal disorders is who pays, public or private. There are several studies that indicate early intervention and altering the amount and frequency of exposure to vibration and/or heavy repetitive tasks can ameliorate the symptoms. ${ }^{23}$ This implies the worker can continue to perform required tasks, though possibly at a reduced level until full/sufficient recovery is achieved. From the perspective of society this would be a more desirable outcome then having these workers develop conditions that prevent them continuing in their tasks, perhaps even permanently, due to their injuries. An earlier study of alternative approaches to treating WC patients demonstrated reduced overall costs. ${ }^{4}$ They compared a 'specialist-direct' system versus a discounted -fee clinic approach for hotel employees and found claims costs were $63 \%$ lower in the specialist-direct system. They also found that paying higher fees along with having appropriate expertise, no treatment delays, and no self-referral, resulted in significant reductions both in costs and unnecessary care. The idea is to avoid a long, protracted struggle that has little benefit to the injured worker or often to the insurer.

\section{Worker well-being considerations}

Perhaps as important as reducing WC outlays is minimizing patient exposure to additional surgical days and anesthetic events. All patients with neuropathies in both upper limb sites bilaterally that required surgical intervention when given a choice of two or four separate surgical events opted for the simultaneous carpal/cubital surgery. This results in an additional patient benefit because total recovery time is reduced relative to recovery from either two (four) operations when the symptoms are unilateral (bilateral). Time to return to work would be drawn out weeks to months. Nevertheless, it is certainly in the interest of the health care system to perform the surgeries on separate days for maximum financial gain. Patients were interviewed at the follow-up and were medically able to return to previous jobs, perhaps the real gold standard of care.

Some workers performed chipping and grinding activities that involved heavy tools with substantial vibration. One worker provided this description of his exposure: 4.5 years using jack hammers for long periods, use of air hammers and plug hole chisels requiring twisting motions for 6-7 hours/day during which time 5000-6000 holes were opened. Other workers that performed manual tasks had long term exposure to vibration and repetitive tasks that was difficult to quantify. Numerous studies have detailed the symptoms that workers develop when exposed to work conditions that demand handgrip with high forces or the use of vibrating tools. ${ }^{12-14,16,24-30}$ Recovery and return to work for injured workers is affected by whether early access to a physician is provided. ${ }^{31}$

CTS is associated with work activities that are repetitive and forceful. ${ }^{1,32}$ CTS and CuTS are the 1st and 2nd most frequently occurring medical conditions in the workplace and therefore important in terms of worker performance and work longevity. It is noteworthy that the Bureau of Labor Statistics (BLS) [33] reported that the number of days away from work due to occupational injury is the highest for CTS. The effects of work-related injury can extend far beyond the physical impact. ${ }^{34,35}$ Access to medical care is not always available and maybe affected by minority status. ${ }^{36}$ While the workers compensation system is designed to be no fault, there remain considerable barriers to timely access to medical treatment. Workers often report physicians do not want to treat patients under the workers compensation system. A panel of the American Association of Orthopedic Surgeons ${ }^{37}$ recommended that in the worker's compensation system: "The treating healthcare provider should be the advocate for the medical well-being of the injured worker. The workers compensation system should be maintained or improved so that the injured worker has timely access to quality health care."

\section{Conclusion}

Perhaps the greatest concern in this age of limited financial resources is that significant savings for all interested parties can be achieved through early medical access for workers. We have shown that the greatest savings of $\$ 200,000$ on average in accumulated expenditures was obtained when the barriers to medical care were removed for workers in Illinois requiring surgery by reducing average TMMI from 47 to 5.7 months. Additional savings result from performing same day unilateral wrist and elbow surgeries thereby reducing surgeon and facility fees, TMMI, surgical exposure, and recovery time.

\section{References}

1. NIOSH. Musculoskeletal Disorders and Workplace Factors. United States Department of Health and Human Services, Washington DC, USA, 1997.

2. Tomaino MM, Brach PJ, Vansickle DP. The rationale for and efficacy of surgical intervention for electrodiagnostic-negative cubital tunnel syndrome. J Hand Surg. 2001;26(6):1077-1081. 
3. Lama M. Carpal tunnel release in patients with negative neurological examinations: clinical and surgical findings. Neurosurgery. 2009;65(4 Suppl):A171-A173.

4. Atcheson SG, Brunner RL, Greenwald EJ, et al. Paying doctors more: Use of musculoskeletal specialists and increased physician pay to decrease workers' compensation costs. J Occup Environ Med. 2001;43(8):672679 .

5. Homan MM, Franzblau A, Werner A, et al. Agreement between symptom surveys, physical examination procedures and electrodiagnostic findings for the carpal tunnel syndrome. Scand $J$ Work Environ Health. 1999;25(2):115-124

6. IWCC. Illinois Workers' compensation Commission ambulatory medical fee schedule. Joint committee on Administrative Rules, Illinois, USA, 2010 .

7. Roquelaure Y, Ha C, Nicolas G, et al. Attributable risk of carpal tunnel syndrome according to industry and occupation in a general population. Arthritis Rheum. 2008;59(9):1341-1348.

8. Clarke JB, Dalby W, Gunn JF. Chipping hammer vibration. Scand J Work Environ Health. 1986;12(4 Spec No):351-354.

9. Zeng-Shun Y, Hu C, Ling Q, et al. Epidemiologic survey of vibration syndrome among riveters, chippers, and grinders in the railroad system of the People's Republic of China. Scand J Work Environ Health. 1986;12(4 Spec No):289-292.

10. Roquelaure Y, Mechali S, Dano C, et al. Occupational and personal risk factors for carpal tunnel syndrome in industrial workers. Scand J Work Environ Health. 1997;23(5):364-369.

11. Bonfiglioli R, Mattioli S, Spagnolo MR, et al. Course of symptoms and median nerve conduction values in workers performing repetitive jobs at risk for carpal tunnel syndrome. Occup Med (Lond). 2006;56(2):115-121.

12. Friden J. Vibration damage to the hand: clinical presentation, Prognosis and lengthy and severity of vibration required. $J$ Hand Surg $\mathrm{Br}$ 2001;26(5):471-474

13. Hartung E, Dupuis H, Sheffer M. Effects of grip and push forces on the acute response of the hand-arm system under vibrating conditions. Int Arch Occup Environ Health. 1993;64(6):463-467.

14. Mirbod SM, Akbar-Khanzadeh F, Onozuka, M, et al. A four-year followup study on subjective symptoms and functional capacities in workers using hand-held grinders. Ind Health. 1999;37(4):415-425.

15. Palmer KT, Harris EC, Coggon D. Carpal tunnel syndrome and its relation to occupation: a systematic literature review. Occup Med (Lond). 2007;57(1):57-66.

16. Shiri R, Miranda H, Heliovaara M, et al. Physical work load and carpa tunnel syndrome: a population-based study. Occup Environ Med. 2009;66(6):368-373.

17. Weislander G, Norback, D, Gothe CJ, et al. Carpal tunnel syndrome (CTS) and exposure to vibration, repetitive wrist movements, and heavy manual work: a case-referent study. Br J Ind Med. 1989;46(1):43-47.

18. Finsen V, Russwurm $H$. Neurophysiology not required before surgery for typical carpal tunnel syndrome. J Hand Surg Br. 2001;26(1):61-64.

19. Witt JC, Hentz JG, Stevens JC. Carpal tunnel syndrome with normal nerve conduction studies. Mus Nerve. 2004;29(4):515-522.
20. Descatha A, Leclerc A, Chastang JF, et al. Incidence of ulnar nerve entrapment at the elbow in repetitive work. Scand J Work Environ Health. 2004;30(3):234-240.

21. Novak CB, Mackinnon SE. Multilevel compression and muscle imbalance in work-related neuromuscular disorders. Am J Ind Med. 2002;41(5):343-352.

22. Omurtag M, Novak CB, Mackinnon SE. Evaluation of Multiple level nerve compression is frequently unrecognized. Can J Plast Surg. 1996;4(3):165-167.

23. Faucett J, Blanc PD, Yelin E. The impact of carpal tunnel syndrome on work status: Implications of job characteristics for staying on the job. J Occup Rehab. 2000;10(1):55-69.

24. Gemme D, Saraste H. Bone and joint pathology in workers using handheld vibrating tools. Scand J Work Environ Health. 1987;13(4):290-300.

25. Greenwald D, Moffit M, Cooper B. Effective surgical treatment of cubital tunnel syndrome based on provocative clinical testing without electrodiagnostics. Plast Reconstr Surg. 2008;104(1):215-218.

26. Harada N, Griffin MJ. Factors influencing vibration sense thresholds used to assess occupational exposures to hand transmitted vibration. $\mathrm{Br} J$ Ind Med. 1991;48(3):185-192.

27. Katz JN, Amick BC, Keller R, et al. Determinants of work absence following surgery for carpal tunnel syndrome. Am J Industr Med. 2005;47(2):120-130.

28. Kihlberg S. Biodynamic response of the hand-arm system to vibration from an impact hammer and a grinder. Int $J$ Ind Ergonomics. 1995;16(1):1-8.

29. Kihlberg S, Attebrant M, Gemme G, et al. Acute effects of vibration from a chipping hammer and a grinder on the hand-arm system. Occup Environ Med. 1995;52(11):731-737.

30. Taylor W. Biological effects of the hand-arm vibration syndrome: Historical perspective and current research. J Acoust Soc Am. 1988;83(2):415-422.

31. Kominski GF, Pourat N, Roby DH, et al. Return to work and the degree of recovery among injured workers in California's workers compensation system. J Occup Environ Med. 2008;50(3):296-305.

32. Tanaka S, Wild DK, Cameron LL, et al. Association of occupational and non-occupational risk factors with the prevalence of self-reported carpal tunnel syndrome in a national survey of the working population. Am J Ind Med. 1997;32(5):550-556.

33. Bureau of Labor Statistics (BLS). Days away from work highest for carpal tunnel syndrome. The Economic Daily (TED), Washington, USA, 2001.

34. Lax MB, Klein R. More than meets the eye: social, economic, and emotional impacts of work-related injury and illness. New Solut. 2008;18(3):343-360.

35. Poole K, Mason H. Disability in the upper extremity and quality of life in hand-arm vibration syndrome. Disabil Rehabil. 2005;27(22):1373-1380.

36. Dembe AE. Access to medical care for occupational disorders: difficulties and disparities. J Health Social Policy. 2001;12(4): 19-33.

37. American Academy of Orthopaedic Surgeons (AAOS). Clinical practice guideline on the diagnosis of carpal tunnel syndrome, California, USA, 2007;pp. 1-73. 